\title{
Treatment tactics in pediatric clavicle fractures
}

\author{
I.I. Gordienko ${ }^{1,2}$, A.V. Sakovich ${ }^{1,2}$, N.A. Tsap ${ }^{1,2}$, A.V. Marfitsin ${ }^{2}$, S.M. Kutepov ${ }^{1}$ \\ ${ }^{1}$ Ural State Medical University, Ekaterinburg, Russian Federation \\ ${ }^{2}$ Children Clinical Hospital \#9, Ekaterinburg, Russian Federation
}

\begin{abstract}
Introduction One of the most common injuries in children is clavicle fractures. They account for up to $14 \%$ of all pediatric bone injuries. Aim Comparative evaluation of the effectiveness of surgical and conservative methods of treating closed clavicle fractures in children. Materials and methods Between 2011 and 2018, 1,800 children with clavicle fractures referred to the traumatology and orthopedic department at the Children's Clinical Hospital No. 9 in Yekaterinburg. Most of them were treated conservatively, and 94 $(5.2 \%)$ children were hospitalized for surgical treatment. Depending on age and type of displacement, children received different conservative treatments, such as Deso dressing in children under two years old, figure-eight-bandage in children over two years of age. Surgical treatment was open reduction of fragments and fixation with either a Kirschner wire or a titanium elastic nail (TEN); titanium plates were used in several cases. For a comparative assessment of the results of the treatment methods for clavicle fractures, two groups of patients were formed. Results Shortening of consolidated clavicle was not observed in children of the main group treated surgically. In several cases, the elongation of the clavicle was revealed by no more than $1 \mathrm{~cm}$. Patients in the comparison group showed shortening of the broken clavicle in three cases, no more than $1.3 \mathrm{~cm}$. Conclusion After surgical treatment, the length of the shoulder girdle was fully restored; insignificant shortening after conservative treatment did not cause functional disorders.
\end{abstract}

Keywords: clavicle, fracture, children, conservative treatment, surgical treatment, Kirschner wire, TEN (titanium elastic nail), plate

\section{INTRODUCTION}

One of the most common pediatric injuries is clavicle fractures which account for up to $14 \%$ of all bone injuries [1-6]. No tendency towards a decrease in the number of the cases in the general structure of injuries has been observed [7]. The majority of adult patients with fractures of the clavicle shaft undergo surgical treatment [8]. In contrast to adults, the periosteum in children is more developed, there is a reliable blood supply and a greater healing potential [5]. Therefore, conservative treatment of closed clavicle fractures in children is very successful and is not accompanied by complications in most cases, $[2,3]$. Despite the abundance of tools proposed for the treatment of clavicle fractures, the question of the preferred method for fixation of clavicle fractures is unresolved [9].

Purpose of the work Comparative evaluation of the effectiveness of surgical and conservative methods of treating closed clavicle fractures in children.

\section{MATERIAL AND METHODS}

Between 2011 and 2018, 1,800 children with clavicle fractures were referred to the traumatology and orthopedic department at the Children's Hospital No. 9 in Yekaterinburg. Most of them were treated conservatively, but $94(5.2 \%)$ children were hospitalized for surgical treatment. The distribution by age was as follows. There were $321(17.9 \%)$ children in the age from six months to two years old; $586(32.5 \%)$ were in the age from two to seven years; $542(30.1 \%)$ were from 7 to 14 years of age and $351(19.5 \%)$ from 14 to 17 years. The number of boy largely prevailed over girls: 1174 $(65.2 \%)$ and $626(34.8 \%)$, respectively. The nature of the injury in the majority of cases was closed fractures, totally $1,788(99.3 \%)$. Open fractures were rare cases and occurred in $12(0.7 \%)$ patients; eight $(0.4 \%)$ of them were treated for primary open fractures. It should be noted that displacement of clavicle fragments was not observed in those cases and the wound resulted from a blow with a heavy object on the clavicle. Those children were mainly treated on an outpatient basis, and only 4 $(0.3 \%)$ children were treated surgically as secondary open fractures of the clavicle.

Depending on the age and type of displacement, children received different conservative treatments. Thus, the upper shoulder girdle was fixed with a Dezo-type bandage for 2-3 weeks in children under two years of age, regardless of the presence and type of displacement of fragments, which ended with excellent results in all children. In the group of children from three to 17 years old with displaced clavicle fractures, the upper shoulder girdle was fixed with an 8-shaped cotton-gauze bandage, tightly sewn between the patient's shoulder blades in the position of shoulder abduction (Fig. 1). In clavicle fractures without displacement of fragments in children over 10 years old, an arm sling bandage was used for fixation. Plaster immobilization for clavicle fractures is out of practical use at our hospital. 
Our study was conducted according to the requirements of the Regulation "On the procedure for conducting biomedical research in humans" (Bulletin of the Higher Attestation Board of the Ministry of Education of Russia, 2002. No. 3. p.73-75).

All hospitalized children with closed clavicle fractures were operated on a delayed basis after a complete clinical examination after two or three days. The main indication for hospitalization was the displacement of fragments along the length by two or more centimeters. Also, the indications for surgical treatment were the threat of skin perforation by bony edges and comminuted fractures in which the fragment was located perpendicular to the axis of the clavicle and there was a potential threat of damage to the neurovascular bundle. Clavicle fractures complicated by lesions of the subclavian vessels, trauma to the brachial plexus or nonunion of fragments were not observed in our practice.

The localization of clavicle fractures which required surgical interventions was various, but in the overwhelming majority of cases it was the middle third of the diaphysis, 58 (61.7\%); there were 27 (28.7\%) acromial fractures and $9(9.5 \%)$ sternal processes at the ends of the clavicle. Open osteosynthesis was performed in 94 children. Intraoperative fixation of a fracture was most often performed with a Kirschner wire, $74(78.7 \%)$ children. Titanium elastic nailing (TEN) was used in $13(13.8 \%)$ children; fixation with a plate was used only in $7(7.4 \%)$ children.
For a comparative assessment of the treatment results in regard to methods, two groups (surgical and comparison) were formed, 20 injured children in each. The criteria for the inclusion of patients in the study were: 1) age from 14 to 17 years; 2) closed uncomplicated fracture of the middle third of the clavicle with displacement of fragments along the length by $2 \mathrm{~cm}$ or more. In the surgical group, children underwent surgical interventions according to relative indications, such as significant displacement of fragments along the length, comminuted fractures and functional need (professional athletes). The operation consisted of a longitudinal approach (up to $8 \mathrm{~cm}$ long) to a fracture, exposure of bone fragments, and of retro-antegrade osteosynthesis of the clavicle with a 2.0-mm Kirschner wire or TEN with a diameter of 2.0 to $3.0 \mathrm{~mm}$ chosen by an attending surgeon.

In the comparison group, patients were treated conservatively by closed reduction of bone fragments under local anesthesia (injection of $2 \%$ lidocaine solution into the hematoma), in the maximum abduction of the shoulder girdle and its further fixation with an eight-shaped bandage. Its stability was achieved by tight suturing along the dorsal surface.

The results were evaluated according to clinical indicators: 1) measurements of the length of the clavicle on the injured and healthy sides; 2) the period of recovery of active movements and the range of motion of the upper limb three months post-surgery. Statistical processing of the data was performed with the basic statistical tools, Microsoft Excel 2017 and Statistica 6.0.

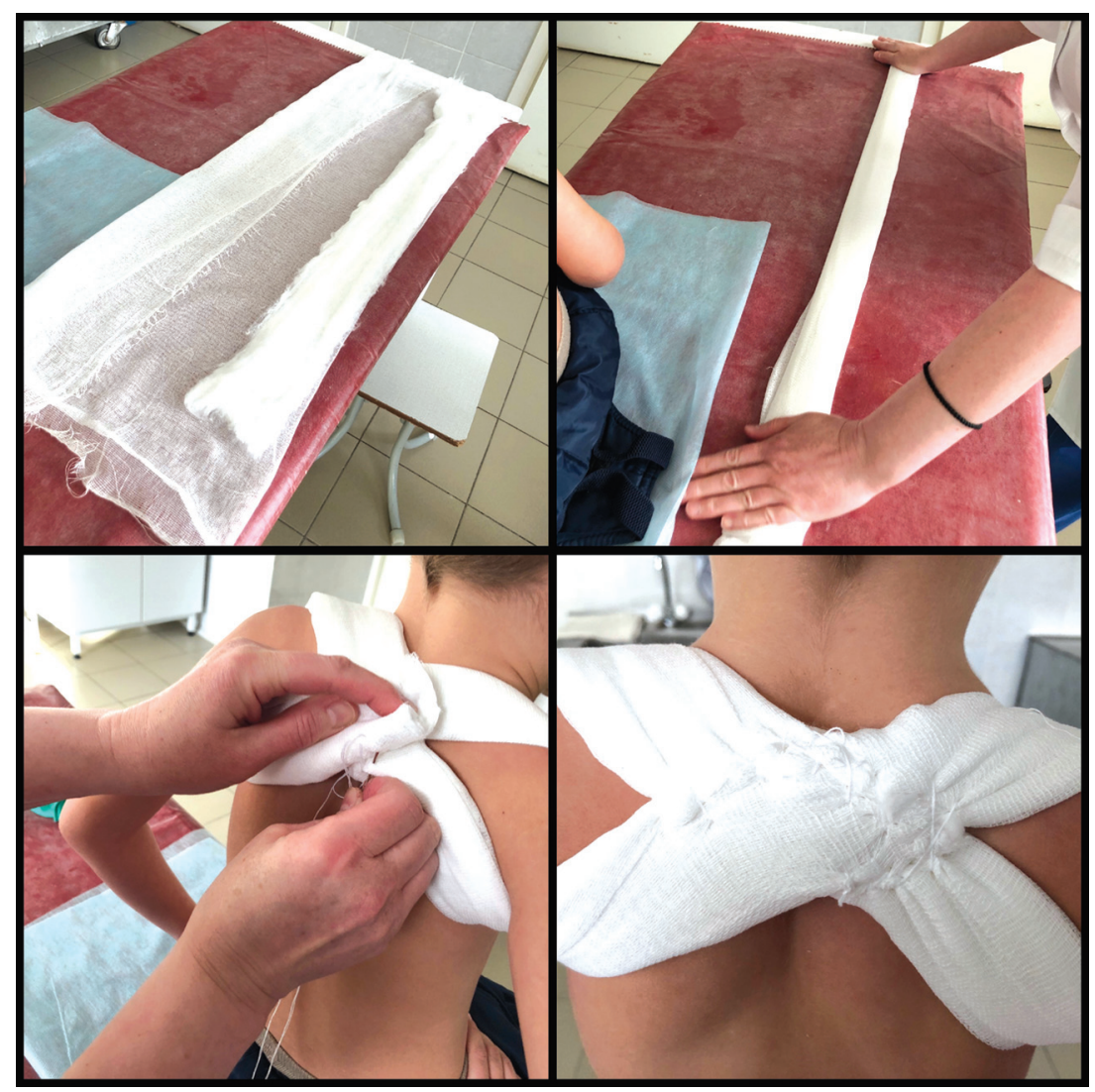

Fig. 1 Fixation of the upper shoulder girdle with a figure-of-eight bandage in a 12 year-old child with a clavicle fracture 


\section{RESULTS}

The functional result is the leading sign of treatment effectiveness. Its assessment in the immediate and longterm periods after treatment showed that the function of the upper limb on the side of the injury was fully restored in all patients in the groups of conservative and surgical treatment. The volume of initial active movements (movements in the shoulder joint without raising the arm above the level of the clavicle) in children of the surgical group was restored on postoperative days 4-5, while in patients of the comparison group the initial active movements were restored by days 6-7. However, a full and painless range of active movements in the shoulder girdle recovered on days 12-14 and 15-16, respectively. The results of the length of healthy and injured clavicles in both groups are presented in Table 1. Table 1 shows that shortening of the consolidated clavicle was not observed in children of the surgical group. There was lengthening of the latter by no more than $1 \mathrm{~cm}$ in several cases. On the contrary, shortening by no more than $1.3 \mathrm{~cm}$ was present in nine cases in the comparison. However, the average difference in the length of the healthy and broken clavicle in patients of the comparison group was $0.3 \mathrm{~cm}$.

Table 1

Comparison of the longitudinal size of the intact and broken clavicle in the groups

\begin{tabular}{|c|c|c|c|c|}
\hline \multirow{2}{*}{ Patient } & \multicolumn{2}{|c|}{ Intact clavicle, cm } & \multicolumn{2}{c|}{$\begin{array}{c}\text { Clavicle after fracture } \\
\text { consolidation, cm }\end{array}$} \\
\cline { 2 - 5 } & $\begin{array}{c}\text { Surgical } \\
\text { group }\end{array}$ & $\begin{array}{c}\text { Comparison } \\
\text { group }\end{array}$ & $\begin{array}{c}\text { Surgical } \\
\text { group }\end{array}$ & $\begin{array}{c}\text { Comparison } \\
\text { group }\end{array}$ \\
\hline 1 & 15.0 & 15.4 & 15.1 & 15.2 \\
\hline 2 & 17.1 & 15.2 & 17.1 & 15.2 \\
\hline 3 & 16.6 & 16.7 & 16.7 & 16.3 \\
\hline 4 & 15.8 & 17.3 & 16.2 & 16.4 \\
\hline 5 & 15.7 & 16.6 & 15.7 & 15.3 \\
\hline 6 & 16.4 & 15.4 & 16.4 & 15.4 \\
\hline 7 & 17.1 & 16.2 & 17.1 & 16.2 \\
\hline 8 & 16.9 & 15.0 & 17.0 & 15.0 \\
\hline 9 & 14.9 & 16.2 & 14.9 & 16.2 \\
\hline 10 & 15.7 & 15.4 & 15.7 & 15.4 \\
\hline 11 & 15.2 & 16.3 & 15.3 & 16.1 \\
\hline 12 & 14.9 & 16.1 & 15.1 & 15.9 \\
\hline 13 & 15.5 & 16.1 & 15.5 & 16.1 \\
\hline 14 & 16.2 & 15.3 & 16.1 & 15.3 \\
\hline 15 & 16.3 & 15.6 & 16.1 & 15.7 \\
\hline 16 & 15.7 & 14.8 & 15.8 & 14.5 \\
\hline 17 & 14.7 & 17.0 & 14.9 & 16.6 \\
\hline 18 & 17.1 & 15.6 & 17.0 & 15.6 \\
\hline 19 & 15.5 & 15.2 & 15.5 & 15.0 \\
\hline 20 & 15.4 & 15.5 & 15.5 & 15.6 \\
\hline Average & 15.885 & 15.879 & 15.935 & 15.65 \\
\hline
\end{tabular}

Note Differences between the values that are insignificant compared with the control group $\mathrm{p} \leq 0.05$.
Case report A 15-year old patient fell from the bike on his left side and sustained a fracture of the left clavicle in its middle third and displacement of fragments along the width and length of $2.5 \mathrm{~cm}$ (Fig. 2).

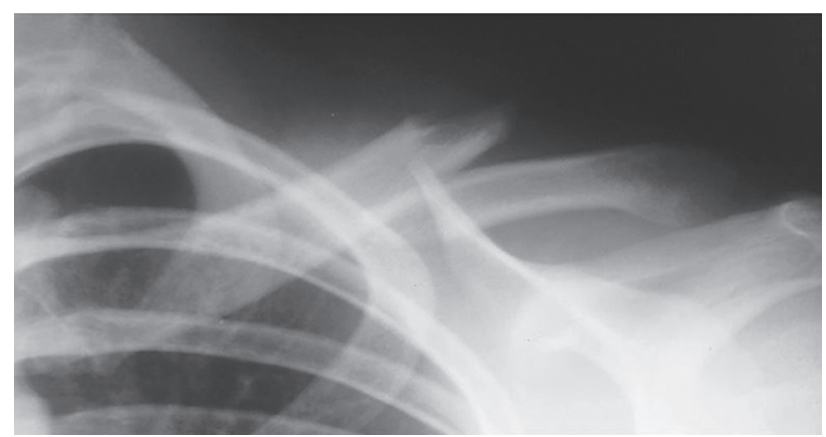

Fig. 2 Anteroposterior radiograph of the left clavicle taken after three hours post-injury. Displaced fracture in the middle third

Closed reduction of the fragments after local anesthesis with $2 \%$ lidocaine solution and fixation with an figure-of-eight bandage sewn tightly on the dorsal surface was performed. In the checking radiographs, the displacement was reduced up to $1 \mathrm{~cm}$ (Fig. 3).

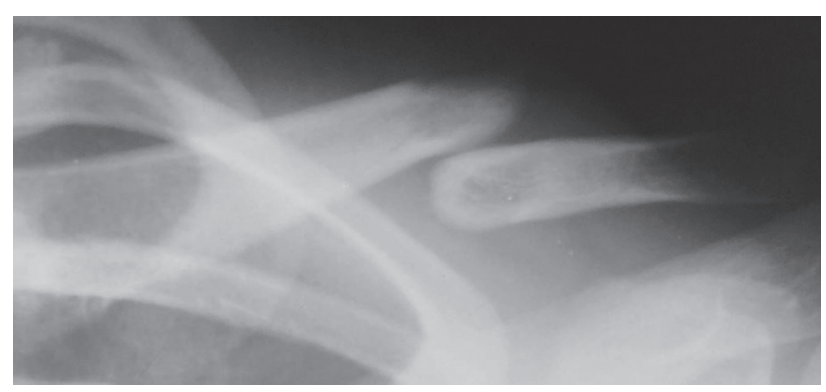

Fig. 3 AP radiograph of the left clavicle after reduction

Full functional recovery was seen three months after the injury. The injured and intact clavicles were of the same length. No deformities were detected (Fig. 4).

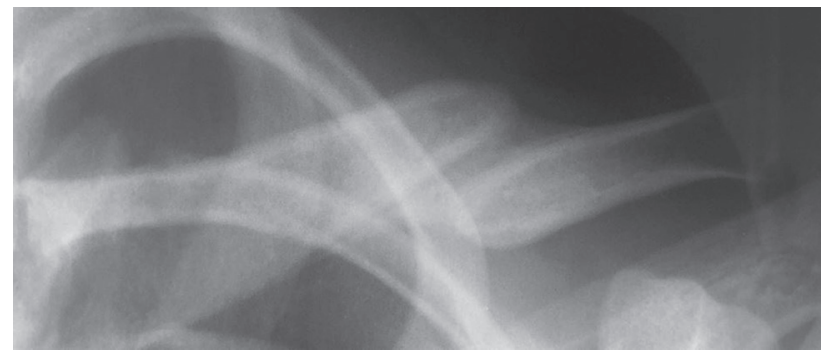

Fig. 4 AP radiograph of the left clavicle three months after the injury

\section{DISCUSSION}

Surgical treatment of clavicle fractures enables to completely restore the length of the shoulder girdle and the functional ability of the upper limb. No significant functional disorders occur in the shoulder girdle in slight residual shortening of the clavicle after conservative treatment. 
The anatomical shape can be fully restored with surgical treatment of clavicle fractures, what is not observed in $40 \%$ of children after conservative treatment due to minor shortening. This fact should be opposed to the anesthetic and infectious risks accompanying open surgery, cosmetic risks due to the presence of a scar in the area of the operation. According to our observations, the absolute indication for surgical treatment is a case of an open fracture associated with damage to the neurovascular bundle and nonunion of the fracture. A relative indication for surgical treatment may be comminuted fractures in patients that need the fastest restoration of active movements due to the nature of their professional activities. The choice of a surgical method is made by an attending physician during the preoperative planning period and depends on the location and type of fracture, the social and neuropsychiatric status of the patient. The displacement amount in length and width as well as the magnitude of the angle of displacement cannot be an absolute indication for surgical treatment. It is possible to effectively use closed reduction of the fragments in a satisfactory position using an eight-shaped bandage. The results of our study are consistent with the data of domestic and foreign literature that shows that clavicle fractures should be treated conservatively in most cases with good and excellent results [5, 6]. However, our material opposes to the point of view of domestic authors in their works about a widespread use of surgical treatment $[1,2,4]$. The results of the present study do not exclude the option of surgical treatment for closed clavicle fractures if there are relative indications. Thus, it might be used according to professional needs, for example, in professional athletes.

\section{CONCLUSION}

1. Surgical treatment of clavicle fractures in children has no obvious advantages over conservative treatment if indications for surgery are relative.

2. Indications for surgical intervention in pediatric fractures of the clavicle must be justified as absolute, or they must be determined by the patient's needs and the patients must be informed about all potential risks of osteosynthesis.

3. Eight-shaped cotton-gauze bandage for clavicle fractures is a method of stable fixation at any amount of displacement of fragments; the efficiency reaches $100 \%$.

\section{REFERENCES}

1. Zorin V.I., Zhila N.G., Petrov G.G. Antropometricheskaia kharakteristika plechevogo poiasa pri perelomakh kliuchitsy u detei [Anthropometric characteristics of the shoulder girdle for fractures of the clavicle in children]. Dalnevostochnyi Meditsinskii Zhurnal [Far Eastern Medical Journal], 2008, no. 4, pp. 59-61. (in Russian)

2. Islentev A.V., Shapar V.D., Strelkov N.S., Kamenskikh M.S. Metod lecheniia perelomov kliuchitsy u detei s pomoshchiu ustroistva dlia repozitsii i fiksatsii [A method of treating clavicular fractures in children using a device for reposition and fixation]. Ortopediia, Travmatologiia i Protezirovanie [Orthopaedics, Traumatology and Prosthetics], 2012, no. 1, pp. 86-87. (in Russian)

3. Alkalaev S.B., Kopysova V.A., Fomichev M.V. Metody lecheniia perelomov kliuchitsy [Methods of treating clavicular Fractures]. Vestnik Novosibirskogo Gosudarstvennogo Universiteta. Seriia: Biologiia, Klinicheskaia Meditsina [Bulletin of the Novosibirsk University. Series: Biology, Clinical Medicine], 2008, vol. 6, no. 3-1, pp. 127-136. (in Russian)

4. Zorin V.I., Zhila N.G. Osobennosti operativnogo lecheniia povrezhdenii i porokov razvitiia kliuchitsy $u$ detei [Special features of surgical treatment of injuries and malformations of the clavicle in children]. Khabarovsk, DGMU [Far Eastern State Medical University] Publ., 2012, 216 p. (in Russian)

5. Stepanyan H., Hennrikus W., Flynn D., Gendelberg D. Complex clavicle fractures in children: Kids are not little adults. Trauma (United Kingdom), 2019, vol. 21, no. 1, pp. 35-39. DOI: 10.1177/1460408617724815

6. Zhila N.G., Komarov P.B., Komarov K.M., Khrulev D.A., Ananev D.V. Sovremennyi podkhod k spitsevoi fiksatsii pri perelomakh kliuchitsy u detei [A modern approach to wire fixation for fractures of the clavicle in children]. Sbornik materialov Resp. Nauch.-prakt. Konf. s mezhdunar. uchastiem, posviashch. 70-letnemu iubileiu d-ra med. nauk, Prof. B.K. Dzhenalaeva "Aktualnye Voprosy Okhrany Zdorovia Detei" [Proceedings of Republican Scientific-Practical Conference with international participation, dedicated to 70-th Anniversary of M.D., Ph.D., Professor B.K. Dzhenalaev “Actual Problems of Child Health Protection»], 2018, vol. 3. (in Russian) Available at: http://elib.zkgmu.kz/xmlui/handle/123456789/328

7. Diushenaliev B.B., Mamytov E.B., Akimbaev M.A. Osteosintez stiagivaiushchimi ustroistvami pri perelomakh kliuchitsy [Osteosynthesis with tightening devices for fractures of the clavile]. Vestnik Kyrgyzsko-Rossiiskogo Slavianskogo Universiteta [Bulletin of the Kyrgyz-Russian Slavic University], 2017, vol. 17, no. 3, pp. 18-19. (in Russian)

8. Tuliaganov D.B., Porsakhonov R.G., Nishonov Kh.T., Nakhavlboev R.T., Mamatkulov Zh.A., Abdurakhmonov B.M. Sluchai uspeshnogo udaleniia spitsy, migrirovavshei v plevralnuiu polost posle osteosinteza kliuchitsy [The case of successful removal of the wire that migrated to the pleural cavity after osteosynthesis of the clavicle]. Vestnik Ekstrennoi Meditsiny [Bulletin of Emergency Medicine], 2019, vol. 12, no. 2, pp. 97-99. (in Russian)

9. Islentev A.V., Shapar V.D., Strelkov N.S., Kamenskikh M.S. Sovremennoe sostoianie voprosa lecheniia patsientov s perelomami kliuchitsy [Current status of the problem related to treatment of patients with clavicular fractures]. Vestnik Eksperimentalnoi $i$ Klinicheskoi Khirurgii [Bulletin of Experimental and Clinical Surgery], 2012, vol. 5, no. 2, pp. 492-496. (in Russian)

Received: 27.01 .2020

\section{Information about the authors:}

1. Ivan I. Gordienko, M.D.,

Ural State Medical University, Ekaterinburg, Russian Federation, Children Clinical Hospital \#9, Ekaterinburg, Russian Federation

2. Anna V. Sakovich, M.D.,

Ural State Medical University, Ekaterinburg, Russian Federation, Children Clinical Hospital \#9, Ekaterinburg, Russian Federation

3. Natalia A. Tsap, M.D., Ph.D., Professor,

Ural State Medical University, Ekaterinburg, Russian Federation, Children Clinical Hospital \#9, Ekaterinburg, Russian Federation, Email: tsapna-ekat@rambler.ru
4. Alexey V. Marfitsin, M.D., Ph.D., Children Clinical Hospital \#9, Ekaterinburg, Russian Federation 5. Sergey M. Kutepov, M.D., Ph.D., Professor, Corresponding Member of RA Sciences,

Ural State Medical University, Ekaterinburg, Russian Federation, Email: usma@usma.ru 